\title{
Effect of symmetrical restoration for the migration of uncemented total hip arthroplasty: a randomized RSA study with 75 patients and 5-year follow-up
}

\author{
Sverrir Kiernan ${ }^{1 *}$ (D), Mats Geijer ${ }^{2,3,4} \mathbb{B}$, Martin Sundberg ${ }^{1}$ and Gunnar Flivik
}

\begin{abstract}
Background: Inferior placement of a femoral stem is predictive for early loosening and failure, but does restoration of the original hip anatomy benefit the function and survival of a total hip replacement?

Methods: Seventy-five patients with primary unilateral hip osteoarthritis operated with an uncemented anatomical stem were randomized for either standard or modular stems. We used 50 ABG II stems with modular necks and 25 standard stems (control group). We measured the symmetry in hip anatomy between healthy and operated side. The anatomical restoration variables were anteversion, global offset, and femoral offset/acetabular offset (FO/AO) quota. We performed measurements using a CT-based 3D templating and measuring software. Migratory behavior of the stems was then measured postoperatively with repeated radiostereometry (RSA) examinations over 5 years.

Results: Both stem types showed an early (within 3 months) good stabilization after an initial slight rotation into retroversion and subsidence. There were no significant differences in RSA migration between modular and standard stems. Postoperative anteversion and FO/AO quota had no impact on stem migration. The standard stem tended to result in insufficient global offset (GO), whereas the modular stem did not.

Conclusions: The modular stem gave good symmetrical anatomical restoration and, like the standard version, a benign migratory behavior. Anteversion, $\mathrm{GO}$, and $\mathrm{FO} / \mathrm{AO}$ quota had no significant impact on stem migration. It therefore seems to be of no importance whether we choose a modular or a standard stem with regard to postoperative stem migration for this stem type. We overestimated the effect anatomical parameters have on stem movement; hence, we believe the study to be underpowered.
\end{abstract}

Trial registration: ClinicalTrials.gov identifier: NCT01512550. Registered 19 January 2012-retrospectively registered, Keywords: THR, THA, RSA, Radiostereometry, Anatomical restoration, 3D-CT

\footnotetext{
*Correspondence: Sverrir.Kiernan@med.lu.se

'Department of Orthopedics, Skåne University Hospital, Clinical Sciences,

Lund University, Lund, Sweden

Full list of author information is available at the end of the article
}

(c) The Author(s). 2020 Open Access This article is licensed under a Creative Commons Attribution 4.0 International License, which permits use, sharing, adaptation, distribution and reproduction in any medium or format, as long as you give appropriate credit to the original author(s) and the source, provide a link to the Creative Commons licence, and indicate if changes were made. The images or other third party material in this article are included in the article's Creative Commons licence, unless indicated otherwise in a credit line to the material. If material is not included in the article's Creative Commons licence and your intended use is not permitted by statutory regulation or exceeds the permitted use, you will need to obtain permission directly from the copyright holder. To view a copy of this licence, visit http://creativecommons.org/licenses/by/4.0/ The Creative Commons Public Domain Dedication waiver (http://creativecommons.org/publicdomain/zero/1.0/) applies to the data made available in this article, unless otherwise stated in a credit line to the data. 


\section{Background}

Restoring hip anatomy is important for function [1-4], but more studies are needed to determine the importance of restoration for survival of the total hip replacement (THR) [1]. An endoprosthesis can better withstand various load factors and function better if positioned according to the original anatomy. Too small femoral offset (FO) is associated with increased acetabular polyethylene wear [5] and improving lever arm biomechanics by increasing FO reduces the load transferred to the cup [6].

Too small $\left(<10^{\circ}\right)$ anteversion appears harmful to the long-term outcome for cemented femoral stems [7]. Leg-length-discrepancy (LLD) can result in biomechanical changes in hip joint load both on the long and the short side, which may cause problems in the long term [8]. The size of clinically significant LLD is however unclear [9]. 2D templating software systems have been developed to facilitate anatomical restoration [10] and there is even an increasing interest to advance from $2 \mathrm{D}$ projections to more accurate 3D measurements [11, 12]. Computer-assisted surgery (CAS) [13] can also be used to facilitate the placement of a prosthesis. The use of modular necks has been suggested to facilitate anatomic restoration [14], but not much is known about other biomechanical effects of increased modularity [15]. Today, there have been no studies reporting the effect of stem modularity on the migratory behavior of the stem. We tested the hypothesis that restoration of the hip anatomy benefits the migration behavior of the stem and that a modular stem system can be beneficial to reach the planned positioning of the implant, reducing the risk of unfavorable biomechanical strain.

\section{Methods}

In a randomized prospective cohort study, we analyzed stem migration with successive RSA examinations during 5 years follow-up. Our study group consisted of 75 patients (48 males, 27 females) with primary osteoarthritis (OA) of the hip undergoing THA between October 2009 and September 2011. Inclusion criteria were patients less than 75 years of age with primary unilateral OA of the hip. We only considered patients with bone quality and morphology of the proximal femur suitable for an uncemented stem, i.e., type A and some type B femurs according to the Dorr classification [16]. Patients who were capable of understanding the conditions of the study with CT-scans and RSA at follow-up and who were willing to participate for the duration of the prescribed follow-up were asked to enroll and had to give their written informed consent to participation. The mean age at the time of operation was 59 (34-80) years and mean BMI was 29 (20-36). Seventy-four out of 149 initial patients did not fulfill the inclusion criteria due to a bone quality and morphology according to our criteria obviously unsuitable for an uncemented stem or due to the fact that a standard stem was inadequate for anatomical restoration as offset of the stem increases with size resulting in incompatibility between offset and size fit (Consort flow Diagram).

We prepared 75 envelopes randomized for 50 modular stems (ABG II modular hip and Trident $^{\circ}$ Acetabular system (Stryker Orthopaedics, Mahwah, New Jersey, USA)) and 25 standard stems (ABG II monolithical ${ }^{\circ}$ and Trident ${ }^{\oplus}$ Acetabular system (Stryker Orthopaedics, Mahwah, New Jersey, USA)) (Fig. 1). The latter was our control group. The ABG II monolithical ${ }^{\circ}$ Hip Stem is an anatomical stem intended for cementless, press-fit application and is designed for the best proximal anatomical fit. The proximal region of the stem is coated with PureFix $^{\circ}$ HA. The standard system includes left and right stems with 8 body sizes ranging from size 1 to size 8 in which offset increases with size. The modular version has the same stem body but comes with enhanced alignment abilities, to choose the most suitable modular neck for extramedullary anatomic fitting.

\section{Computed tomography}

We performed two separate CT scans pre- and postoperatively using a low-dose technique, with an effective radiation dose exposed to the patient equivalent to that of conventional radiography [17]. CT was performed directed over the pelvis and hips, and a separate scan covering the knees. The pelvic scan was planned from

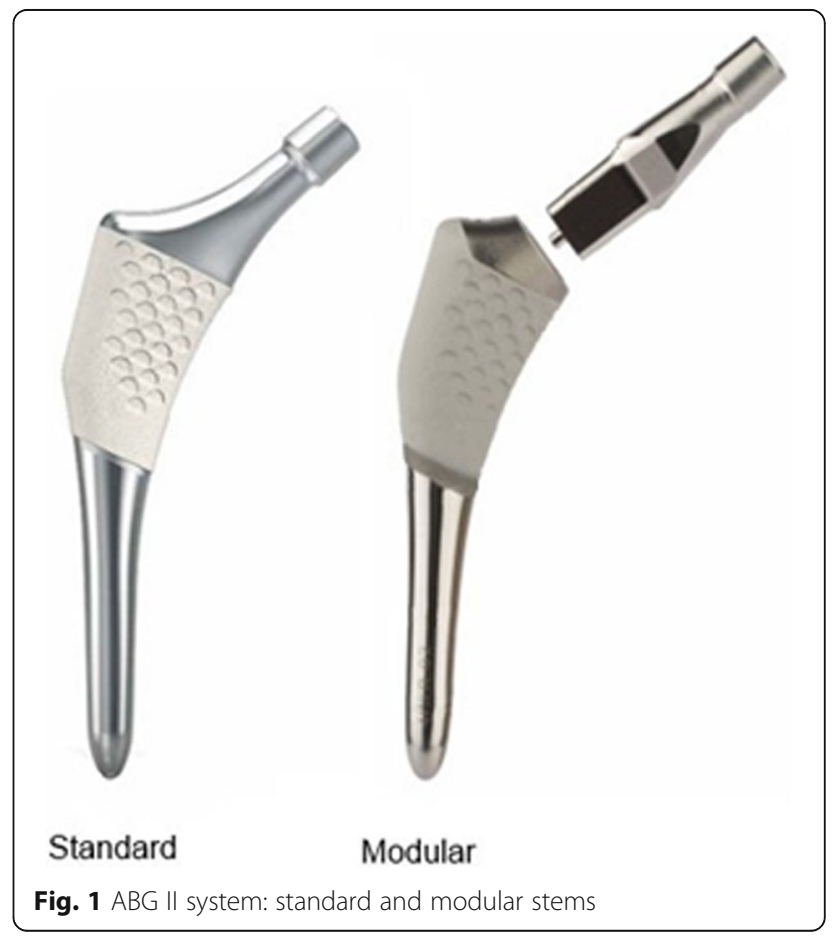


slightly cranial to the superior anterior iliac spine to about $3 \mathrm{~cm}$ below the lesser trochanter. The knee scan aimed at inclusion of the femoral condyles and a few centimeters of the proximal tibia. We performed the CT on a multi-detector helical Brilliance 64 CT scanner (Philips, Eindhoven, The Netherlands). We used lowdose settings for the preoperative study and a mediumdose setting to compensate for the implanted prosthesis for the postoperative study. CT dose index by volume (CTDIvol) was set as 4.8 for the preoperative hip study and 4.2 for the preoperative knee study, whereas CTDIvol was 16.4 for the postoperative hip study to compensate for the hip arthroplasty but the knee dose was unchanged.

\section{Preoperative templating}

The surgeon did a preoperative 2D templating based on conventional calibrated radiographs. The X-rays were produced in a standardized manner where we centered the anteroposterior view of the pelvis on the symphysis pubis, with toes touching to control femoral rotation. The templating was done with the contralateral healthy hip anatomy as reference but also in part based on the measurements previously done on preoperative 3D-CT measurements. This gave the surgeons the means to choose the correct stem size, and in the case of the modular stems, with enhanced alignment abilities, to choose the most suitable modular neck for extramedullary anatomic fitting.

For templating, we used Sectra IDS7 PACS Orthopaedic Package $^{\mathrm{TM}}$ (Sectra AB, Linköping, Sweden).

\section{Surgical procedure}

Two experienced hip surgeons performed the operations through a posterolateral approach. Before stem implantation, we marked the proximal femur with 9 to 10 tantalum markers (diameter $0.8 \mathrm{~mm}$ ), with 3 to 4 in the lesser trochanter and 5 to 6 in the greater trochanteric area.

The ABG II modular stem is anatomical and cementless and therefore orients itself into best proximal fit. However, well in place, the surgeons had the option to use one of three neck versions (retroverted, standard, and anteverted) in order to mimic the contralateral healthy hip with preoperatively measured (3D-CT) anteversion (Fig. 2). Anatomical restoration of global offset was attempted to mimic the global offset of the contralateral healthy hip measured during the preoperative $2 \mathrm{D}$ templating procedure (Fig. 3).

\section{D-CT measurements}

An independent observer made all measurements on pre- and postoperative 3D-CT without knowledge of

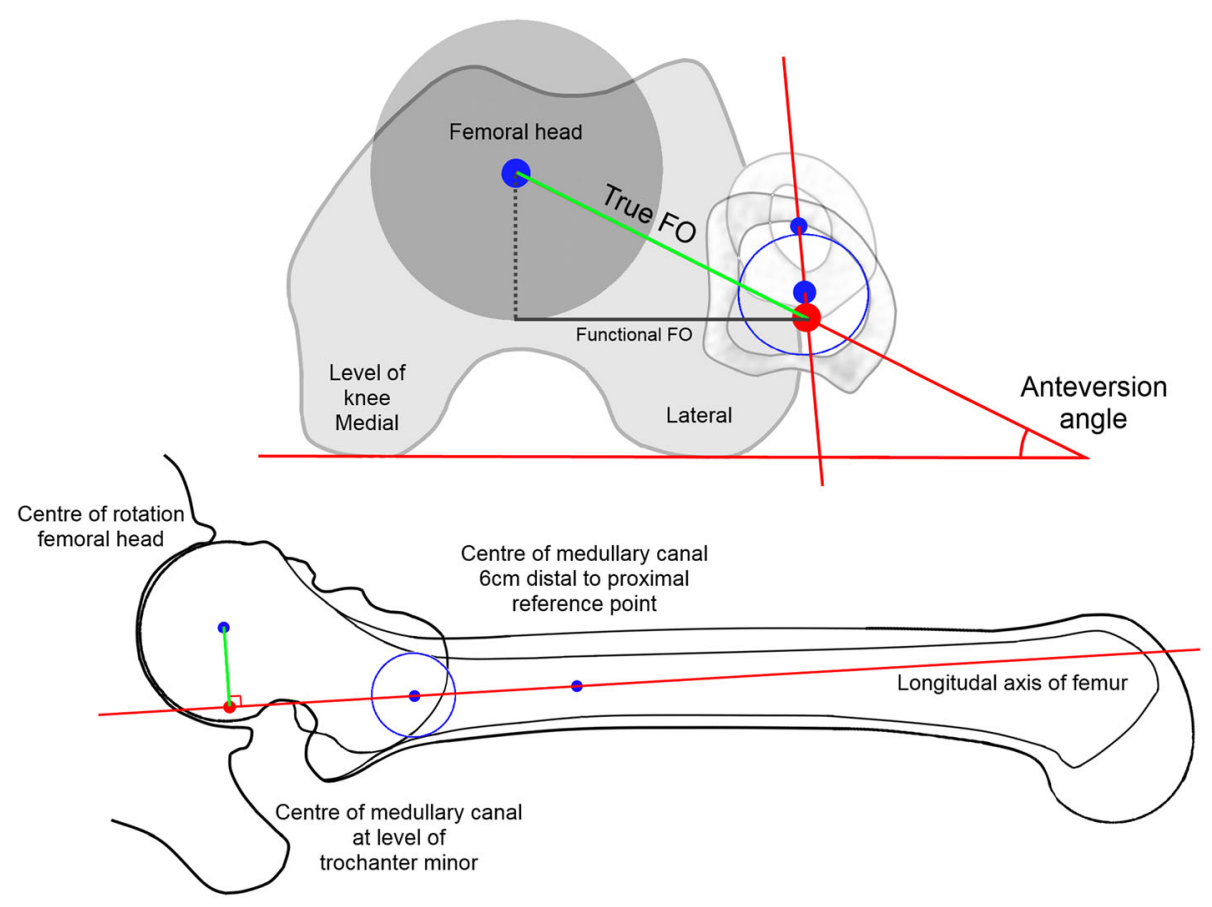

Copyright 2016 Sverrir Kiernan

Fig. 2 Reference points for 3D-CT measurement of anteversion. A proximal reference point in the center of the medullary canal at the lower level of trochanter minor and a second $3 \mathrm{~cm}$ more distal reference point in the center of the medullary canal formed the longitudinal axis of the femur. The perpendicular line (femoral offset) runs from the longitudinal axis of the femur to the center of rotation. The hip anteversion is the angle between this perpendicular line in relation to the posterior femoral condylar line 


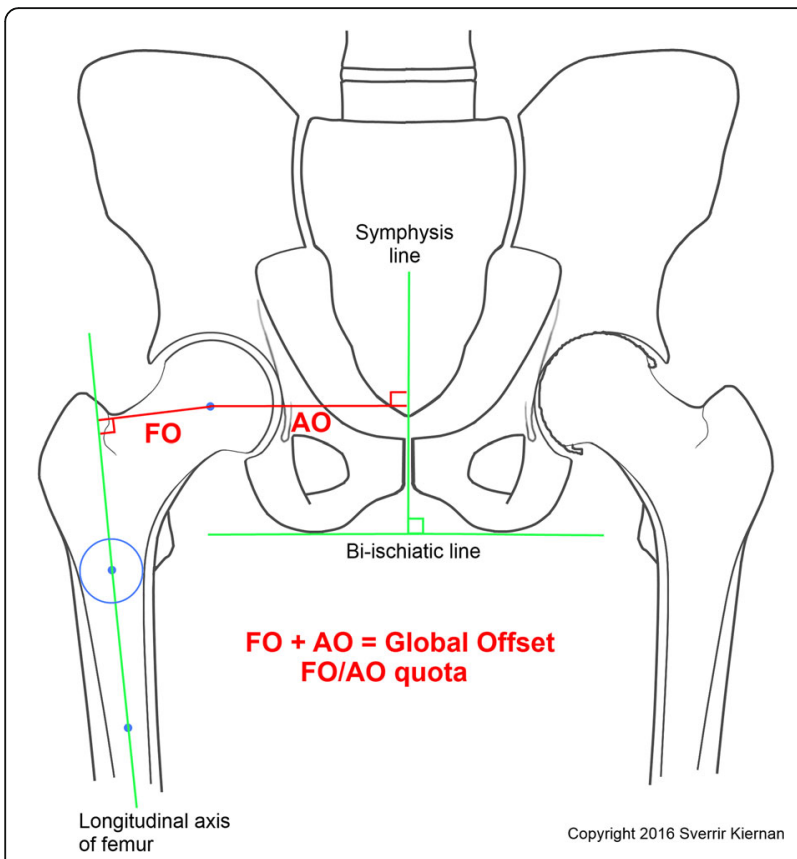

Fig. 3 Femoral offset (FO) is the distance between the longitudinal axis of the femur to the center of rotation. Acetabular offset $(A O)$ is the distance between the center of rotation to the symphysis line. Global offset is the $\mathrm{FO}$ plus the $\mathrm{AO}$

previous measurements and had no knowledge or involvement in preoperative $2 \mathrm{D}$ templating or the patients' management. The pre- and postoperative 3D-CT examinations were assessed for lever arms and rotatory positions of the stems, using a CT-based 3D templating software (Ortoma Plan $^{\text {TM }}$, Gothenburg, Sweden). This software gives validated highly accurate measurements for these variables. The interrater reliability results for the 3D-CT measures were generally near perfect for all our variables with high interclass correlation coefficients $(0.887$ to 0.974$)$ and narrow confidence intervals for the two raters. We will report these results in a separate paper. The variables for anatomical restoration were the symmetry of anteversion, global offset, and the FO/AO quota in relation to the healthy hip.

\section{Radiostereometric analysis}

RSA was carried out using a uniplanar technique with the patient supine [18]. Two X-ray sources were fixed, mounted to the ceiling. We used a type-41 calibration cage (Tilly Medical, Lund, Sweden) and the MBRSA 4.0 computer software version 4.0 (Leiden, Holland). We used model-based RSA (MBRSA, Leiden, Netherland) with an elementary geometry shape (EGS) to add two fictive markers to the stem, one at the tip of the stem and one in the center of rotation in the head of the prosthesis. The reference examination was performed on the first postoperative day and served as the reference for all further analyses. Follow-up examinations were carried out after 2 weeks, 3 months, and at 1, 2, and 5 years, with a time tolerance of $5 \%$ at each interval. We set the cut-off level for the exclusion of patients or of specific examinations at a condition number of 150 (An expression for how well spread the tantalum markers are in the segment. Better spread will result in lower $\mathrm{CN}$ and more reliable RSA results). For the mean error of rigid body fitting (an expression for marker stability), the cut-off level was set at 0.3 [19].

RSA values were expressed as migration (rotation and translation) about/along the 3 axes in an orthogonal coordinate system ( $6^{\circ}$ of freedom) and referred to as transverse ( $x$-axis), longitudinal ( $y$-axis), and sagittal ( $z$-axis). We considered distal translation (subsidence) and longitudinal rotation (both in/about the $y$-axis) as primary effect variables for how the stem migrates. We had 75 double examinations for precision assessment of our RSA measurements (Table 1).

\section{Statistical analysis}

We used a variance adjusted mixed model to analyze migrating behavior in relation to stem type (Fig. 4a) where we treated patient ID as a random effect. We used logistic regression to analyze postoperative anatomical symmetry. We were interested in whether better symmetry (where the non-operated leg was a reference) in anteversion, global offset, and FO/AO quota were significant factors to influence postoperative stem migration (Fig. 4b). When evaluating the impact of individual anatomical discrepancies on the probability of becoming at risk for increased postoperative stem migration, we chose to classify anteversion symmetry within the range of $-2.5^{\circ}$ to $+2.5^{\circ}$ discrepancy between hip sides. Likewise, we set the range for GO symmetry to -2.5 to $+2.5 \mathrm{~mm}$ between sides. We used Fisher's exact test to evaluate the difference in anatomical restoration regarding stem type and examined distribution histograms for precision estimates (Fig. 4c). We conducted all calculations in STATA s (IC v12 and v13).

\section{Results}

\section{Radiostereometric analysis}

The mean migration rates for all stems after each follow-up period are summarized in Table 2 and further divided into subgroups of stem types.

Table 1 Precision of radiostereometric analysis for assessment of stem migration

\begin{tabular}{lll}
\hline Axis & Translation $(\mathbf{m m})^{*}$ & Rotation $\left({ }^{\circ}\right)^{*}$ \\
\hline Transverse $(x)$ & 0.23 & 0.46 \\
Longitudinal $(y)$ & 0.18 & 1.14 \\
Sagittal $(z)$ & 0.30 & 0.24 \\
\hline
\end{tabular}

*Precision of measurements based on 75 double investigations. Given number represents the smallest migration value that is considered significant and is based on 2 standard deviations of the error obtained. This, hence, represents the $95 \%$ confidence limit 


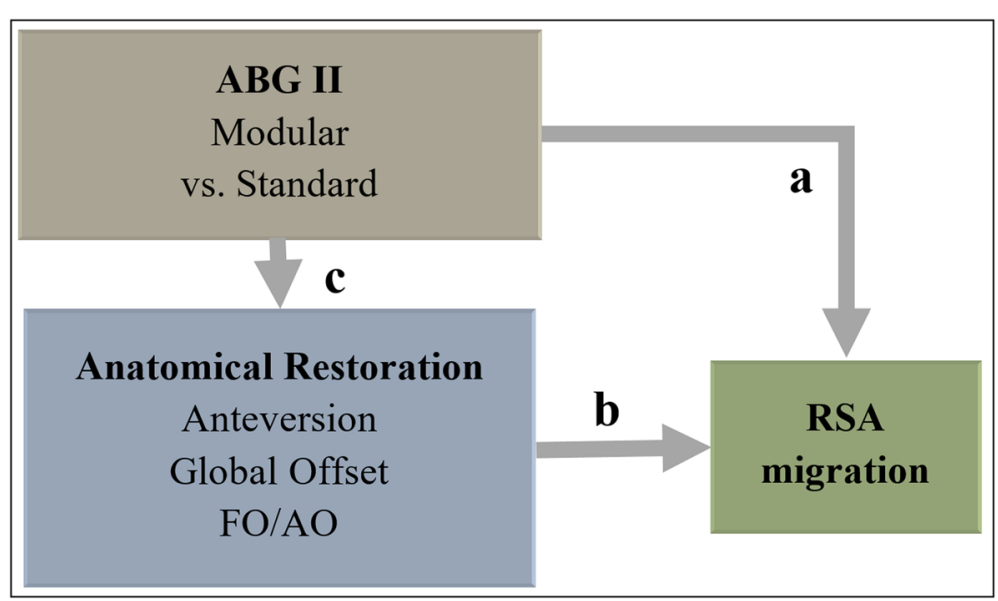

Fig. 4 Overview of statistical analysis and variables

Table 2 Results of RSA

Mean stem migration (Stdev) in relation to direct postoperative reference examination

Early migration Late migration

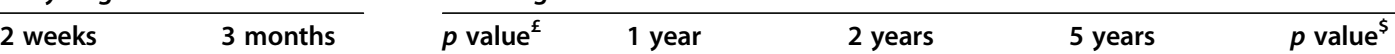

\section{Rotation ( $\left.{ }^{\circ}\right)$}

$X$-axis

\begin{tabular}{|c|c|c|c|c|c|c|c|}
\hline All stems & $0.15(0.52)$ & $0.15(0.65)$ & 0.13 & $0.09(0.67)$ & $0.17(0.61)$ & $0.27(0.79)$ & 0.01 \\
\hline Modular stems & $0.12(0.52)$ & $0.11(0.65)$ & 0.54 & $0.01(0.67)$ & $0.12(0.61)$ & $0.16(0.79)$ & 0.18 \\
\hline Standard stems & $0.21(0.49)$ & $0.24(0.72)$ & & $0.27(0.72)$ & $0.28(0.66)$ & $0.51(0.68)$ & \\
\hline \multicolumn{8}{|l|}{-axis } \\
\hline All stems & $0.66(1.27)$ & $1.03(1.51)$ & $<0.001$ & $1.05(1.41)$ & $1.23(1.60)$ & $1.47(1.70)$ & $<0.001$ \\
\hline Modular stems & $0.61(1.27)$ & $1.07(1.51)$ & 0.35 & $1.11(1.41)$ & $1.32(1.60)$ & $1.56(1.70)$ & 0.93 \\
\hline Standard stems & $0.76(1.49)$ & $0.95(1.67)$ & & $0.92(1.61)$ & $1.03(1.97)$ & $1.25(2.02)$ & \\
\hline \multicolumn{8}{|l|}{-axis } \\
\hline All stems & $-0.56(0.57)$ & $-0.69(0.68)$ & $<0.001$ & $-0.70(0.71)$ & $-0.75(0.77)$ & $-0.82(0.77)$ & $<0.001$ \\
\hline Modular stems & $-0.55(0.57)$ & $-0.69(0.68)$ & 0.74 & $-0.69(0.71)$ & $-0.76(0.77)$ & $-0.81(0.77)$ & 0.62 \\
\hline Standard stems & $-0.60(0.70)$ & $-0.69(0.82)$ & & $-0.72(0.83)$ & $-0.74(0.95)$ & $-0.84(0.89)$ & \\
\hline \multicolumn{8}{|l|}{ ranslation $(\mathrm{mm})$} \\
\hline \multicolumn{8}{|l|}{-axis } \\
\hline All stems & $0.16(0.25)$ & $0.18(0.26)$ & $<0.001$ & $0.18(0.27)$ & $0.20(0.29)$ & $0.23(0.30)$ & 0.001 \\
\hline Modular stems & $0.14(0.25)$ & $0.18(0.26)$ & 0.50 & $0.16(0.27)$ & $0.19(0.29)$ & $0.21(0.30)$ & 0.15 \\
\hline Standard stems & $0.21(0.29)$ & $0.19(0.32)$ & & $0.22(0.33)$ & $0.21(0.39)$ & $0.28(0.33)$ & \\
\hline \multicolumn{8}{|l|}{-axis } \\
\hline All stems & $-0.76(0.83)$ & $-1.00(1.10)$ & $<0.001$ & $-1.00(1.12)$ & $-0.89(1.21)$ & $-0.92(1.11)$ & 0.09 \\
\hline Modular stems & $-0.70(0.83)$ & $-0.88(1.10)$ & 0.17 & $-0.88(1.12)$ & $-0.84(1.21)$ & $-0.86(1.11)$ & 0.77 \\
\hline Standard stems & $-0.90(0.89)$ & $-1.25(1.21)$ & & $-1.25(1.22)$ & $-1.01(1.49)$ & $-1.05(1.07)$ & \\
\hline \multicolumn{8}{|l|}{-axis } \\
\hline All stems & $0.01(0.26)$ & $0.03(0.34)$ & 0.22 & $0.06(0.42)$ & $0.02(0.40)$ & $0.01(0.44)$ & 0.66 \\
\hline Modular stems & $0.00(0.26)$ & $-0.02(0.34)$ & 0.02 & $-0.03(0.42)$ & $-0.04(0.40)$ & $-0.09(0.44)$ & 0.03 \\
\hline Standard stems & $0.03(0.23)$ & $0.14(0.43)$ & & $0.25(0.51)$ & $0.14(0.53)$ & $0.23(0.48)$ & \\
\hline
\end{tabular}

${ }^{f} p$ values for estimates of changes before 3 months representing the period when the stem settles in place

${ }^{5} p$ values for estimates of changes from 3 months after surgery during which osseous integration and stabilization should have occurred 
The whole group showed a statistically significant mean early stem subsidence of $1.00 \mathrm{~mm}$ and average stem retroversion by $1.03^{\circ}$ within the first 3 postoperative months $(p<.0001$ and $p<.0001$, respectively). After that, until the 5-year follow-up, the stems rotated slightly further to an average of $1.47^{\circ}(p<.0001)$, while no more subsidence occurred after 3 months $(p=0.09)$ (Fig. 5, Table 2).

\section{Migrating behavior}

\section{ABG II modular vs. standard}

Comparing the modular and standard designs, we found no difference regarding neither retroversion nor subsidence (Fig. 6, Table 2).

\section{Postoperative anatomical symmetry}

Postoperative stem anteversion and FO/AO quota had no impact on late postoperative stem migration.

We found no differences in postoperative stem migration related to how well hip symmetry was restored with regard to anteversion and $\mathrm{GO}$.

\section{Stem type vs. symmetry}

When comparing different stem types, there was no difference regarding symmetrical anteversion restoration $(p$ $=0.20)$ nor symmetrical GO restoration $(p=0.32)$. However, compared to the modular stem, the standard stem had a tendency towards a lower GO on the operated side compared to the contralateral side $(p=0.00)$.

\section{Discussion}

The results indicate an early stabilization of both stem types after an initial rotation into slight retroversion while subsiding.

The two stem types showed equal potential in restoring anteversion- and GO symmetry within the range of $\pm 2.5^{\circ}$ and $\pm 2.5 \mathrm{~mm}$ between sides. Further, there was no indication that neither anteversion- nor GO symmetry influenced postoperative migration. It therefore seems to be of no importance whether we choose a modular or a standard stem with regard to postoperative stem migration.

The stem of the ABG system is designed for a close anatomical proximal fit in the femur, which makes the stem version difficult to direct without modular options. Further, the standard stem has an offset that increases with size but limits the possibility for achieving a predetermined stem orientation. Stryker recalled the modular version of the ABG II system in June 2012 due to the potential for fretting and corrosion at the stem-neck junction [19]. A monolithic (standard) system with different offset and anteversion choices can compensate for the increased capabilities of a modular system to provide surgeons with options regarding anatomical restoration. With these increased options, we believe that a reliable preoperative template plan can give sufficient precision and accuracy in stem positioning regardless of what stem you use. We did not have preoperative access to the CT-based 3D templating software (Ortoma Plan ${ }^{\mathrm{TM} \text { ) }}$ which we later used to measure our anatomical parameters. Preoperative CT measurements done by a radiologist functioned as a guide for the surgeons during $2 \mathrm{D}$ templating and surgery. An asset to this study was that the observer, orthopedic surgeon, which made the radiological measurements for this study based on Ortoma Plan ${ }^{\mathrm{TM}}$ was not involved in patients' clinical follow-up and did not take part in their management. 3D templating software is superior to $2 \mathrm{D}$ templating because it gives information on hip version, and likewise, the conception of true femoral offset can be improperly assessed during 2D templating as well [20].

Although 3D-CT makes it possible to measure the leg length difference taking into account points in the hip, knee, and ankle for various positions of the legs and any

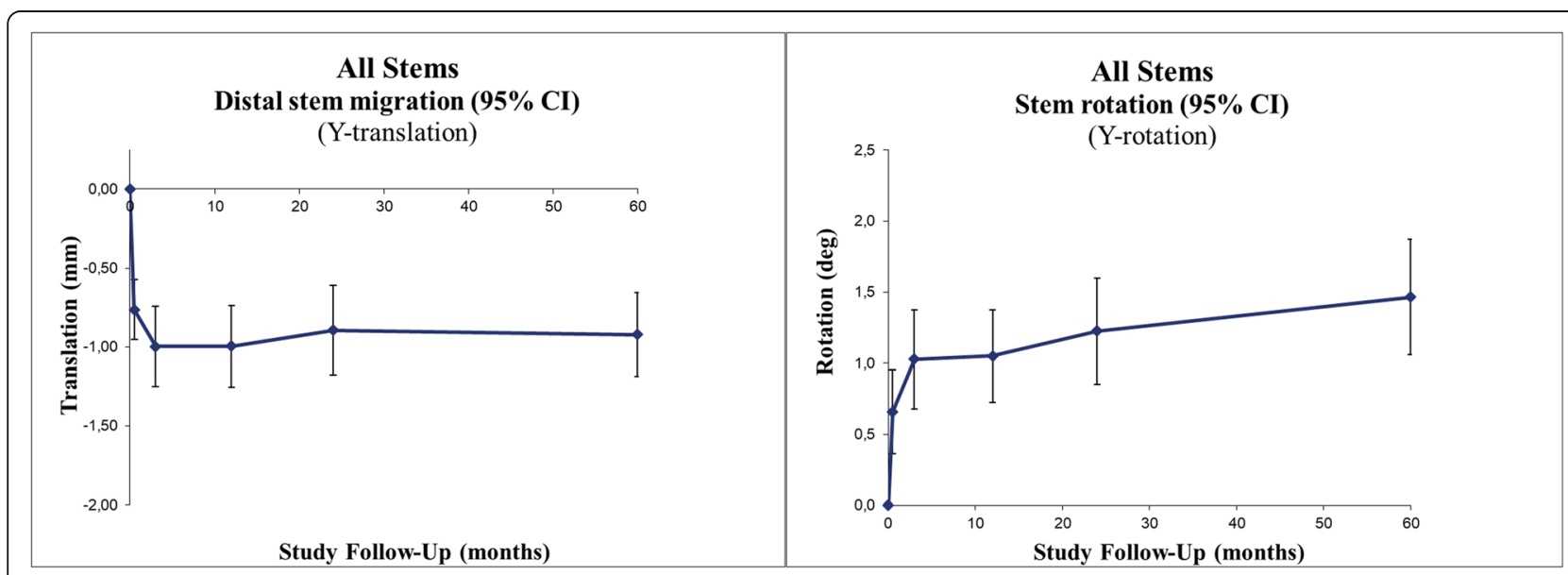

Fig. 5 Line charts with 95\% confidence intervals 


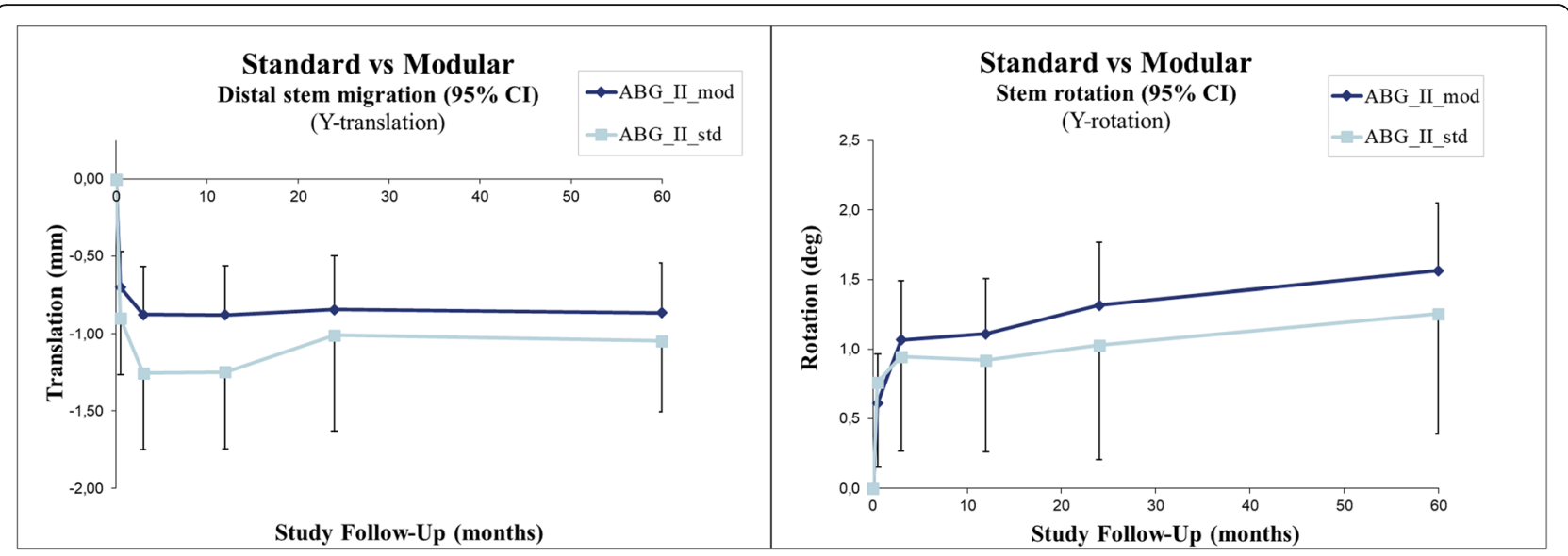

Fig. 6 Line charts with 95\% confidence intervals

valgus/varus deformities, we did not include the ankle in our CT analysis, and therefore, we could regrettably not include LLD in our study. There have been concerns regarding choosing appropriate and reproducible anatomical landmarks for 3D-CT measurements of anteversion caused by variability in dimension and contours of anatomical structures $[21,22]$. This is particularly true for the trochanteric area proximal to the trochanter minor. We, therefore, decided to put the proximal reference point at the lower level of trochanter minor. The center is easily reproduced at this level whereas the medullary canal becomes more circular. We believe this better represents the longitudinal axis of the stem.

In the design of this study, we overestimated the effect anatomical parameters would have on the stem movement. The study design was underpowered for detecting the minor effect that anatomical parameters possibly have on postoperative migration of uncemented stems.

With the purpose of achieving better symmetry, it could be argued that a limitation of this study is the lack of divergence in anatomical restoration. This and the good stability of the stem used makes it hard to find any clinically important differences regarding stem migration. Based on our data, we cannot conclude to what degree we must restore symmetry to gain adequate stability for prosthetic parts. We will continue to evaluate the functional benefit of anatomical restoration by analyzing our study subjects further with data obtained from 3D gait analysis and correlate with different factors of anatomical reconstruction.

\section{Conclusions}

Our results show a generally good symmetrical anatomical restoration and a benign migratory behavior with early stabilization for both types of the ABG II stem. Modular stems may allow better precision in GO reconstruction.

\section{Abbreviations}

AO: Acetabular offset; CAS: Computer-assisted surgery; EGS: Elementary geometry shape; FO: Femoral offset; FO/AO: Femoral offset/acetabular offset quota; GO: Global offset; LLD: Leg-length-discrepancy; OA: Osteoarthritis; RSA: Radiostereometrical analysis; THR: Total hip replacements

\section{Acknowledgements}

We thank Tommy Schyman, medical statistician, Clinical studies Region Skåne, for statistical analysis and Håkan Leijon, a research engineer at our biomechanics lab, for RSA analysis.

\section{Authors' contributions}

Sverrir Kiernan: Planning, collection of data, and data analysis. Writing of manuscript. Mats Geijer: Radiological analysis and writing a paragraph for computed tomography. Supervision of CT analysis protocol and measurements for interrater analysis for mine and his measurements. Martin Sundberg and Gunnar Flivik: Planning of study, performing surgery, critical comments, and help in writing of the manuscript. The author(s) read and approved the final manuscript.

\section{Funding}

The Southern Healthcare Region in Sweden (Södra Sjukvårdsregionen) provided a doctoral grant for labor costs. Stryker gave financial support for part of RSA examinations but did not influence how we conducted or interpreted our study. Open access funding provided by Lund University.

\section{Availability of data and materials}

The principal investigator, Dr. S. Kiernan, had full access to all of the data in the study and takes responsibility for the integrity of the data and the accuracy of the data analysis.

\section{Ethics approval and consent to participate}

The Ethics Committee of Lund University approved the study, and it was carried out in compliance with the Helsinki Declaration of 1975, as revised in 2000 and registered in ClinicalTrials.gov Identifier: NCT01512550.

\section{Consent for publication}

Not applicable

\section{Competing interests}

Dr. S. Kiernan and Dr. G. Flivik have both served as advisory consultants for Ortoma $A B$ during software development. The other authors declare that they have no competing interests.

\section{Author details}

'Department of Orthopedics, Skåne University Hospital, Clinical Sciences, Lund University, Lund, Sweden. ${ }^{2}$ Department of Radiology, Institute of Clinical Sciences, Sahlgrenska Academy, University of Gothenburg, Gothenburg, Sweden. ${ }^{3}$ Department of Radiology, Region Västra Götaland, 
Sahlgrenska University Hospital, Gothenburg, Sweden. ${ }^{4}$ Department of Clinical Sciences, Lund University, Lund, Sweden.

Received: 2 December 2019 Accepted: 28 May 2020

Published online: 17 June 2020

\section{References}

1. Cassidy KA, Noticewala MS, Macaulay W, et al. Effect of femoral offset on pain and function after total hip arthroplasty. J Arthroplast 2012; 27: 18631869. 2012/07/20. DOI: S0883-5403(12)00310-5; https://doi.org/10.1016/j.arth. 2012.05.001 [doi]

2. Iversen MD, Chudasama N, Losina $E$, et al. Influence of self-reported limb length discrepancy on function and satisfaction 6 years after total hip replacement. J Geriatr Phys Ther 2011; 34: 148-152. 2011/09/23. DOI: https:// doi.org/10.1519/JPT.0b013e31820e16dc [doi] 00139143-201107000-00007.

3. Rosler $\mathrm{J}$ and Perka C. The effect of anatomical positional relationships on kinetic parameters after total hip replacement. Int Orthop 2000; 24: 23-27. 2000/04/25

4. Terrier A, Levrero Florencio F and Rudiger HA. Benefit of cup medialization in total hip arthroplasty is associated with femoral anatomy. Clin Orthop Relat Res 2014; 472: 3159-3165. 2014/07/18. DOl: https://doi.org/10.1007/ s11999-014-3787-3 [doi].

5. Little NJ, Busch CA, Gallagher JA, et al. Acetabular polyethylene wear and acetabular inclination and femoral offset. Clin Orthop Relat Res 2009; 467: 2895-2900. 2009/05/05. DOl: https://doi.org/10.1007/s11999-009-0845-3 [doi].

6. Charles MN, Bourne RB, Davey JR, et al. Soft-tissue balancing of the hip: the role of femoral offset restoration. Instr Course Lect 2005; 54: 131-141. 2005/ $06 / 14$

7. Kiernan $\mathrm{S}$, Hermann $\mathrm{KL}$, Wagner $\mathrm{P}$, et al. The importance of adequate stem anteversion for rotational stability in cemented total hip replacement: a radiostereometric study with ten-year follow-up. Bone Joint J 2013; 95-B: 2330. 2013/01/12. DOI: 95-B/1/23; https://doi.org/10.1302/0301-620X.95B1. 30055 [doi]

8. Wretenberg $P$, Hugo A and Brostrom E. Hip joint load in relation to leg length discrepancy. Med Devices (Auckl) 2008; 1: 13-18. 2008/07/01.

9. Maloney WJ and Keeney JA. Leg length discrepancy after total hip arthroplasty. J Arthroplasty 2004; 19: 108-110. 2004/06/11. DOI: S0883540304001366.

10. Scheerlinck T. Primary hip arthroplasty templating on standard radiographs. A stepwise approach. Acta Orthop Belg 2010; 76: 432-442. 2010/10/27.

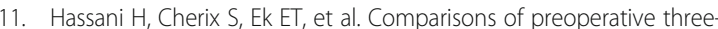
dimensional planning and surgical reconstruction in primary cementless total hip arthroplasty. J Arthroplast 2014; 29: 1273-1277. 2014/02/08. DOI: S0883-5403(14)00005-9; https://doi.org/10.1016/j.arth.2013.12.033 [doi].

12. Mainard D, Barbier $O$, Knafo $Y$, et al. Accuracy and reproducibility of preoperative three-dimensional planning for total hip arthroplasty using biplanar low-dose radiographs: A pilot study. Orthop Traumatol Surg Res 2017; 103: 531-536. 2017/03/23. DOl: S1877-0568(17)30068-3; https://doi.org/ 10.1016/j.otsr.2017.03.001 [doi].

13. El Bitar YF, Jackson TJ, Lindner D, et al. Predictive value of robotic-assisted total hip arthroplasty. Orthopedics 2015; 38: e31-e37. 2015/01/23. DOI: https://doi.org/10.3928/01477447-20150105-57 [doi].

14. Sakai T, Sugano N, Ohzono K, et al. Femoral anteversion, femoral offset, and abductor lever arm after total hip arthroplasty using a modular femoral neck system. J Orthop Sci 2002; 7: 62-67. 2002/01/31. DOI: https://doi.org/10. 1007/s007760200010 [doi].

15. Muller M, Abdel MP, Wassilew Gl, et al. Do post-operative changes of neckshaft angle and femoral component anteversion have an effect on clinical outcome following uncemented total hip arthroplasty? Bone Joint J 2015; 97-B: 1615-1622. 2015/12/08. DOl: 97-B/12/1615; https://doi.org/10.1302/ 0301-620X.97B12.34654 [doi]

16. Dorr LD, Faugere MC, Mackel AM, et al. Structural and cellular assessment of bone quality of proximal femur. Bone 1993; 14: 231-242. 1993/05/01. DOI: 8756-3282(93)90146-2

17. Geijer M, Rundgren $G$, Weber $L$, et al. Effective dose in low-dose $C T$ compared with radiography for templating of total hip arthroplasty. Acta Radiol 2017; 58: 1276-1282. 2017/03/30. DOl: https://doi.org/10.1177/ 0284185117693462 [doi].

18. Valstar ER, Gill R, Ryd $L$, et al. Guidelines for standardization of radiostereometry (RSA) of implants. Acta Orthop 2005; 76: 563-572. 2005/10/
01. DOI: V42136W7L1733G68; https://doi.org/10.1080/17453670510041574 [doi].

19. Molloy DO, Munir S, Jack CM, et al. Fretting and corrosion in modular-neck total hip arthroplasty femoral stems. J Bone Joint Surg Am 2014; 96: 488-493. 2014/03/22. DOI: 1840111; https://doi.org/10.2106/JBJS.L.01625 [doi].

20. Weber M, Woerner ML, Springorum HR, et al. Plain radiographs fail to reflect femoral offset in total hip arthroplasty. J Arthroplast 2014; 29: 1661-1665. 2014/05/27. DOI: S0883-5403(14)00195-8; https://doi.org/10.1016/j.arth.2014. 03.023 [doi].

21. Hermann $\mathrm{KL}$ and Egund N. CT measurement of anteversion in the femoral neck. The influence of femur positioning. Acta Radiol 1997; 38: 527-532. 1997/07/01

22. Murphy SB, Simon SR, Kijewski PK, et al. Femoral anteversion. J Bone Joint Surg Am 1987; 69: 1169-1176. 1987/10/01.

\section{Publisher's Note}

Springer Nature remains neutral with regard to jurisdictional claims in published maps and institutional affiliations.
Ready to submit your research? Choose BMC and benefit from:

- fast, convenient online submission

- thorough peer review by experienced researchers in your field

- rapid publication on acceptance

- support for research data, including large and complex data types

- gold Open Access which fosters wider collaboration and increased citations

- maximum visibility for your research: over $100 \mathrm{M}$ website views per year

At BMC, research is always in progress.

Learn more biomedcentral.com/submissions 